\title{
TERMINOLOGIA BILÍNGUE DESIGNATIVA DAS PROFISSÕES DA HOTELARIA
}

\author{
Antônio Roberto Ferreira Aragão, Ananda Hyngia Nascimento Dos Santos \\ Instituto Federal de Educação, Ciência e Tecnologia do Ceará - IFCE \\ <robertofaragao@gmail.com>,<ananda.hyngia@hotmail.com>
}

DOI: 10.21439/conexoes.v11i5.1255

\begin{abstract}
Resumo. Esta pesquisa fundamentou-se na Terminologia, disciplina pertencente à Linguística, e na Hotelaria. Apresentou-se como objetivo geral a elaboração de um glossário bilíngue de termos designativos das profissões da Hotelaria do português do Brasil e do espanhol da Espanha. O trabalho desenvolveu-se a partir de pesquisas exploratória, bibliográfica e documental por meio das quais elaborou-se um inventário constituído de 18 verbetes das profissões designativas da Hotelaria, com relevante presença de termos não dicionarizados nas grandes obras lexicográficas do português do Brasil. Identificou-se, também, a variação da equivalência de alguns termos em espanhol considerando alguns países que utilizam o referido idioma como língua oficial.
\end{abstract}

Palavras-chaves: Terminologia bilíngue. Profissões da Hotelaria.

\begin{abstract}
This research was based on Terminology, a discipline belonging to Linguistics, and Hospitality. The general objective was the elaboration of a bilingual glossary of designative terms of Portuguese from Brazil and Spanish from Spain for the professions of Hospitality. The work was developed based on exploratory, bibliographic and documentary researches through which an inventory was elaborated consisting of 18 entries of the Hospitality professions, with relevant presence of terms that were not mentioned in the major lexicographic works of Portuguese from Brazil. It was also identified the variation of the equivalence of some terms in Spanish considering some countries that use this language as an official language.
\end{abstract}

Keywords: Bilingual terminology. Hospitality Professions.

\section{INTRODUÇÃO}

Este texto correlaciona duas importantes áreas: de um lado a Terminologia, disciplina pertencente à Linguística; do outro, por sua vez, a Hotelaria, área ligada às ciências sociais aplicadas. O estudo sobre Terminologia e Terminografia realizado pelas autoras Krieger e Finatto (2004) contribuiu sobremaneira para a elucidação dos conceitos abordados neste texto. No âmbito da terminologia monolíngue e bilíngue com enfoque em léxicos relacionados à Hotelaria e ao Turismo, não se pode deixar de mencionar Gomes (2009), Freitas (2009), Nogueira (2009), Silva (2010), Alves (2013), Azevedo (2012). Destaca-se também Oliveira e Spena (2012) para as consultas relacionadas às profissões da Hotelaria.
Objetivou-se elaborar um glossário bilíngue de termos técnicos designativos das profissões da Hotelaria no português do Brasil e no espanhol da Espanha. Com isso, pretendeu-se, de forma específica, descrever os termos da referida terminologia, considerando sua equivalência com o segundo idioma proposto. Objetivou-se também estudar aspectos semântico-morfológicos envolvidos.

O estudo foi de extrema importância para promover a sistematização, a organização e a divulgação de um repertório bilíngue de termos provenientes das profissões da Hotelaria, contribuindo na melhoria do entendimento entre profissionais da área, considerando as dificuldades na comunicação com estrangeiros que utilizam o espanhol como língua oficial.

Partiu-se do seguinte questionamento: os termos de- 
signativos das diferentes profissões da Hotelaria em língua portuguesa do Brasil apresentam equivalentes em língua espanhola da Espanha? As reflexões mostraram que esses termos possuem equivalentes em língua espanhola da Espanha, muitos dos quais ainda não estão devidamente registrados nas grandes obras lexicográficas brasileiras e uma parte significativa apresentou variação em espanhol quanto ao uso em diferentes países que utilizam o idioma como oficial.

A etapa de pesquisa exploratória iniciou-se mediante o contato com profissionais especializados no assunto, docentes e pessoas que vivem em países que têm o espanhol como idioma oficial, proporcionando o levantamento e a definição do corpus constituinte. A pesquisa bibliográfica enfatizou os seguintes temas: Teoria da Terminologia, Terminografia e Hotelaria. Na fase documental, foram utilizados sítios eletrônicos que forneceram informações principalmente sobre as profissões da Hotelaria

\section{A TERMINOLOGIA MODERNA}

Em 1930, o engenheiro alemão Eugen Wuster estabeleceu os pressupostos teóricos para a criação da Terminologia moderna, disciplina que estuda o conjunto de termos e expressões especializadas de uma determinada área de estudo. Conforme Krieger e Finatto (2004, p. 20), "a Terminologia é uma disciplina que possui seu objeto primordial definido: o termo técnico-científico".

A Terminografia, por sua vez, representa a parte prática da Terminologia, ou seja, ela é responsável pela elaboração de glossários, bancos de dados terminológicos e dicionários técnico-científicos. Os glossários são, de uma forma geral, listas de termos técnicos de alguma especialidade ordenadas de forma alfabética, contendo definições e remissivas. Podem ser monolíngues, bilíngues ou multilíngues.

Há diversos trabalhos realizados no âmbito da Terminologia, entre os quais mencionam-se: Silva (2010 apresentou um estudo voltado aos termos e às expressões técnicas da governança hoteleira; Freitas (2009) abordou os termos técnicos da coquetelaria no setor hoteleiro; Gomes (2009) pesquisou os termos e as expressões técnicas do setor hoteleiro com enfoque na recepção; Nogueira (2009) desenvolveu um glossário de sobremesas luso-brasileiras; Matos (2001) elaborou um trabalho sobre a terminologia do caranguejo; Nuvens (2006) apresentou um glossário semibilíngue da terminologia da cana-de-açúcar; Farias (2003) descreveu os termos da moda; e Alves (2013) desenvolveu um miniglossário de termos e expressões técnicas da vinicultura.

\section{PROFISSÕES DA HOTELARIA COM ENFO- QUE NOS HOTÉIS DE GRANDE PORTE}

$\mathrm{Na}$ Hotelaria as profissões são organizadas e distribuídas conforme seus respectivos departamentos. Por exemplo, gerente de hospedagem, supervisor de recepção, recepcionista, capitão-porteiro, concierges, mensageiros, governanta executiva, supervisor de lavanderia e rouparia, lavadores, passadeiras/calandristas, roupeiros, supervisor de andares e áreas, camareiras e auxiliar de serviços gerais são profissões que fazem parte do departamento de hospedagem. Maître, segundo maître, sommelier, bartender, chefe de fila, garçom, commis, chefe de cozinha, subchefe, garde manger, confeiteiro chefe, confeiteiro, cozinheiro, auxiliar de cozinha, chefe de limpeza, gerente de eventos e seus auxiliares, montadores e garçons de eventos são organizados no departamento de alimentos e bebidas. Gerente de vendas e marketing e coordenador/assistente compõem o departamento de vendas e marketing do hotel. Engenheirochefe, supervisor de manutenção, bombeiro hidráulico, eletricista, pintor e marceneiro são organizados no departamento de manutenção. Controller, seus assistentes e auxiliares administrativos atuam no departamento de controladoria do hotel. Gerente de segurança, supervisores e agentes desempenham suas atividades no departamento de segurança do estabelecimento hoteleiro.

Segundo Oliveira e Spena (2012, p. 59), é importante, ainda, acrescentar que as atribuições e responsabilidades de cada cargo podem variar de acordo com o tipo e porte do meio de hospedagem, além da questão do estabelecimento ser independente ou administrado por uma rede hoteleira, o que influencia a atuação dos profissionais envolvidos. É importante salientar que a organização de todos os profissionais em seus devidos departamentos é imprescindível para um bom desempenho da atividade hoteleira.

\section{GLOSSÁRIO BILÍNGUE DE TERMOS DAS PROFISSÕES DA HOTELARIA}

A estrutura do glossário é composta por dezoito termos designativos das profissões da Hotelaria de grande porte. Os termos-entrada foram grafados no português do Brasil, em negrito e em maiúscula, seguidos de seus respectivos equivalentes no espanhol da Espanha, indicados pelo termo "Esp", em negrito. Foram organizados em ordem alfabética, tomando por base os verbetes em língua vernácula, e a maioria desses apresentou variantes em seu uso, conforme utilizados por cada país. Em alguns dos verbetes, constam notas de natureza linguística e para a definição das referências gra- 
TERMINOLOGIA BILÍNGUE DESIGNATIVA DAS PROFISSÕES DA HOTELARIA

maticais, utilizaram-se as siglas "s.m." para substantivo masculino, "s.f." para substantivo feminino e "s.2.g." para substantivo de dois gêneros. Para a indicação de dicionarização do termo, foram utilizadas as seguintes abreviações: TDAC (Termos Dicionarizados com Acepção Complementar); TDAE (Termos Dicionarizados com Acepção Equivalente); TDAD (Termos Dicionarizados com Acepção Diferente); e TND (Termos Não Dicionarizados). Utilizou-se como fonte e referência lexicográfica o dicionário eletrônico Aurélio.

Para uma melhor compreensão, os verbetes foram divididos em quatro subdomínios: Administração, Alimentos e Bebidas, Hospedagem e Vendas. A microestrutura adotada foi composta por elementos obrigatórios, caracterizados pelo símbolo “+” (mais) e opcionais simbolizados pelo " \pm ” (mais ou menos).

Tabela 1: Microestrutura do glossário.

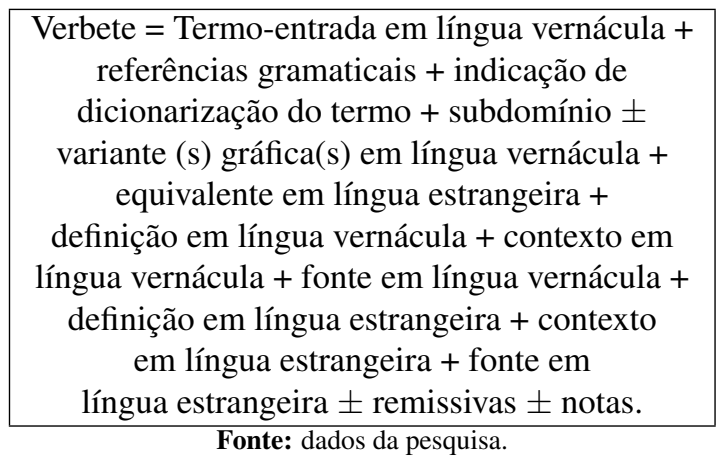

ASSISTENTE DE EVENTOS $s .2 g$. (TND; Alimentos e Bebidas)

Esp. Asistente de eventos.

Profissional responsável pelo planejamento e organização de eventos.

"Veridiana tem passagens por importantes redes hoteleiras, começando a carreira como assistente de Marketing e Vendas, e passando para assistente de eventos e coordenadora de Eventos no Blue Tree Park Cabo de Santo Agostinho".

<http://www.revistahotelnews.com.br/portal/painel do_mercado.php?req_url=007\&id_mercado=841\%

22id_mercado $=841 \% 22$ id_mercado $=841 \backslash \mathrm{T} 1 \backslash$

textquotedblright $\backslash T 1 \backslash$ textquotedblleftid_mercado=

841>.

Profesional responsable por el planeamiento y organización de los eventos.

"Neuvoo España proporciona 11 plazas de Asistente de Eventos en la comunidad autónoma de Madrid. Envía tu aplicación ahora y gana la posición perfecta para ti”.

$<$ http://neuvoo.es/empleos/

trabajo-de-Asistente-de-Eventos-en-Madrid>.

Nota: $\mathrm{Na}$ Venezuela e na Colômbia, para se referir a essa profissão, utiliza-se o termo auxiliar de eventos; no Chile, utiliza-se asistente de producción de eventos; e, em El Salvador, utiliza-se ayudante de eventos.

ATENDENTE DE RESERVAS $s .2 g$. (TND; Vendas)

Esp. Asistente de reservaciones.

Profissional responsável por controlar e realizar todos os procedimentos de reservas, bem como confirmar, alterar e, se necessário, cancelar reservas, checar a ocupação do hotel, influenciar e negociar com clientes.

"No entanto, em hotéis de menor porte e em pousadas, como o quadro de funcionários é mais enxuto, o recepcionista pode acumular funções, como as de atendente de reservas, telefonista e mensageiro, por exemplo".

<http://www.cpt.com.br/cursos-hotelaria/artigos/

hotelaria-atendente-de-reservas-e-suas-funcoes $>$

Profesional responsable de realizar todos los procedimientos de reservas y de manejar el pago que los clientes depositan para garantizar las reservas.

"Este departamento es el encargado de captar y manejar las solicitudes de reservas, esta compuesto por un gerente de reservaciones quien supervisa y dirige el buen desempeño del departamento y los asistentes de reservaciones, los cuales realizaran funciones de atender las reservaciones que lleguen por los diferentes medios de comunicación, las reservas de grupo, las reservas de agencias de Internet o tour operadoras, manejar el dinero proveniente de los depósitos correspondientes para garantizar las reservas”.

$<\mathrm{http}$ //html.rincondelvago.com/reservas-en-hoteles.

html>

Nota: No México, para se referir a essa profissão, utiliza-se o termo encargado de reservaciones; e, na Colômbia, utiliza-se asistente de reservas.

\section{AUDITOR NOTURNO s.m. (TND; Hospedagem)}

Esp. Auditor nocturno.

Profissional responsável pela realização de deveres contábeis de fim de expediente, verificando e corrigindo quaisquer discrepâncias ocorridas no turno anterior e oferecendo um bom atendimento ao hóspede, podendo atuar também como recepcionista em horários mais calmos.

" $O$ bom auditor noturno é aquele que trabalha com imparcialidade e que passa confiança a todos os departamentos dos hotéis". 
TERMINOLOGIA BILÍNGUE DESIGNATIVA DAS PROFISSÕES DA HOTELARIA

\begin{tabular}{l}
\hline$<$ http://www.portaleducacao.com.br/ \\
\hline turismo-e-hotelaria/artigos/18726/ \\
\hline caracteristicas-da-auditoria-noturna> \\
Profesional responsable de verificar los movimientos \\
del dia fijándose si todo están en orden y corrigiendo \\
los errores, por manejar las necesidades de contabilidad \\
en el final de día y, algunas veces, por recieber los \\
huéspedes por la noche.
\end{tabular}

"Nombre del Puesto: Auditor Nocturno Hoteles Barcelona".

<http://es.jobomas.com/

auditor-nocturno-hoteles-barcelona_iid_37937201>.

BARMAN s.m. (TND; Alimentos e Bebidas)

Esp. Barman.

Profissional responsável por elaborar diferentes drinques, misturando diversos sabores com aroma e cor específicos e exclusivos.

"Deve-se salientar que, na pesquisa, registrou que, nos hotéis de pequeno porte, não se encontram determinadas ocupações. Assim: na de restaurante, não há primeiro maître, chefe de bar, chefe de fila, sommelier, chefe de copa de andar, barman, garçom de bar, cambuzeiro e commis de bar".

<https://www.revistas.usp.br/rta/article/viewFile/

\section{3/66037>}

Profesional responsable de preparar, en la barra, las bebidas y también los platos combinados, los bocadillos y los aperitivos sensillos.

"Los camareros ejercen su actividad tanto en grandes como en medianas y pequeñas empresas del sector de la hostelería y de la restauración, en empresas de catering y de organización de eventos. Camarero de bar-cafetería o restaurante, empleado de economato, barman, jefe de banquetes, ayudante de sumiller $y$ auxiliar de servicios en medios de transporte (cruceros, trenes, aviones...) son algunos de los puestos de trabajo que pueden desempeñar".

<http://www.avanzaentucarrera.

com/llegaraser/guia-de-profesiones/

profesiones-de-hosteleria-y-turismo/

camarero-barman/>

Nota 1: O referido termo é proveniente da língua inglesa.

Nota 2: Na Colômbia e no Peru, utiliza-se o termo bartender; e, na Venezuela, utiliza-se tanto bartender como barman.

CAMAREIRA s.f. (TDCE; Hospedagem)

Esp. Camarera de piso.

Profissional responsável por limpar, organizar e garan- tir um apartamento arejado, confortável e acolhedor.

"Em hotéis com programa de troca de toalhas e roupas de cama programada, em que o hóspede sinaliza quando deseja que tudo seja trocado, a arrumadeira/camareira deve verificar se o cliente quer que a troca seja feita ou não." (Hotel: Serviços em Hotelaria, 2012, p. 81).

Profesional responsable de limpiar las habitaciones.

"Las camareras de piso se encargan de que cada habitación esté impecable, que todo esté limpio y en su sitio para que el cliente se sienta como en su casa. En algunos casos también se ocupan del lavado y planchado de sábanas y toallas, en los establecimientos donde existe este servicio."

$<$ http://www.avanzaentucarrera.

com/llegaraser/guia-de-profesiones/

profesiones-de-hosteleria-y-turismo/

camarera-de-pisos/>

Nota: No México, para se referir a essa profissão, utilizam-se os termos mucama, camarista o marera; na Venezuela, na Colômbia e no Peru, utiliza-se camarera; e, em El Salvador, utiliza-se тисата.

\section{CONCIERGE s.2g. (TND; Hospedagem)}

Esp. Conserje.

Profissional responsável por controlar os serviços da portaria e atender aos hóspedes em qualquer horário, referente a qualquer pedido dentro da legalidade e da ética, estando disponível 24 horas.

"A palavra concierge é de origem francesa e significa 'guardião das chaves'." (Hotel: Serviços em Hotelaria, 2012, p. 71).

Profesional responsable de garantizar la seguridad de las llaves, de los servicios de conserjería, de la distribución de equipajes de los huéspedes y de ofrecerlos una atención máxima.

"Álvaro Canales, empleado del hotel de lujo Casa Fuster de Barcelona, es uno de los finalistas del premio internacional Andy Pongco, que distingue el mejor conserje del mundo menor de 35 años."

$<$ http://www.elperiodico.com/es/noticias/barcelona/ empleado-hotel-barcelona-opta-premio-mejor-। conserje-2883369>

Nota 1: O referido termo é proveniente da língua francesa.

Nota 2: Em espanhol, podem ser utilizados conserje ou conserge.

DIRETOR DE ALIMENTOS E BEBIDAS s.m. (TND; Alimentos e Bebidas)

Esp. Director de alimentos y bebidas. 
TERMINOLOGIA BILÍNGUE DESIGNATIVA DAS PROFISSÕES DA HOTELARIA

Profissional responsável por controlar e supervisionar todos os setores de Alimentos e Bebidas.

"O Sheraton Rio Hotel \& Resort, localizado na capital fluminense, anunciou a contratação de Jerónimo Ferreira como seu novo Diretor de Alimentos e Bebidas." $<$ http://www.revistahoteis.com.br/

sheraton-rio-tem-novo-diretor-de-ab/>

Profesional responsable de gestionar todo el departamento de Alimentos y Bebidas.

"Jefe de economato y bodega. Jefe de comedor/director de restauración o banquetes. Jefe de compras. Director de producción. Director de alimentos y bebidas. Responsable de alimentación. Responsable de alimentación en un catering. Consultor". (Guía sectorial de la formación de profesionales en España, 2002, p. 609).

Nota: O referido termo pode ser utilizado como diretor de $A \& B$

\section{GERENTE GERAL $s .2 g$. (TND; Administrativo)}

Esp. Director del hotel.

Profissional responsável por manter o hotel funcionando, decidir sobre tarifas, administrar despesas e estabelecer as normas a serem seguidas pelos setores operacional, administrativo e de vendas.

"As variáveis são muitas e cabe ao gerente geral estar o tempo todo avaliando hóspedes, funcionários, concorrentes e buscando alternativas para manter o negócio rentável”. (Hotel: Serviços em Hotelaria, 2012, p. 60).

Profesional responsable de coordinar todos los servicios de hotel, además de coordinar, organizar, planificar o controlar todos los servicios que su hotel ofrece y todas sus acciones comerciales.

"En nuestro país hay una amplia tradición en el campo de la formación dentro del sector turístico en general $y$ de la dirección de hoteles en particular. Una de las vías más habituales para formarse como director de hotel es estudiar un Grado en Turismo y luego cursar un Máster de Especialización en Dirección Hotelera”. $<$ http://www.avanzaentucarrera.

com/llegaraser/guia-de-profesiones/

profesiones-de-hosteleria-y-turismo/director-de-hotel/

$>$.

Nota: No México, na Venezuela, na Colômbia, em El Salvador e no Peru, para se referir a essa profissão, utiliza-se o termo gerente general.

GERENTE DE HOSPEDAGEM $s .2 g$. (TND; Hospedagem)

Esp. Jefe de alojamiento.
Profissional responsável por gerenciar a área de recepção e de governança de um hotel.

"A função de gerente de hospedagem envolve a gestão de duas importantíssimas áreas de um hotel, a recepção e a governança, ambas com imenso contato presencial com o hóspede”. (Hotel: Serviços em Hotelaria, 2012, p. 61).

Profesional responsable de coordinar al Jefe de recepción y a la Gobernanta del hotel.

"Desde nuestro punto de vista el Jefe de Alojamiento debe ser: Un buen gestor de equipos coordinando los departamentos de Pisos y Recepción y encargándose de la buena imagen de estos".

$<$ http://www.cesae.es/blog/

las-5-claves-de-los-puestos-de-trabajo-en-hoteles\ -el-jefe-de-alojamiento>.

Nota: No México, para se referir a essa profissão, utiliza-se o termo encargado del alojamiento; e, na Venezuela, na Colômbia e em El Salvador, utiliza-se gerente de hospedaje.

\section{GOVERNANTA s.f. (TDAD; Hospedagem)}

Esp. Gobernanta.

Profissional responsável por administrar a limpeza e organização do hotel, gerenciar, treinar e orientar os colaboradores que trabalham no setor, objetivando oferecer aos hóspedes um serviço de qualidade.

"A governanta deve ser uma profissional equilibrada e flexível para poder lidar com situações inesperadas da melhor forma possível”. (Hotel: Serviços em Hotelaria, 2012, p. 75).

Profesional responsable de dirigir y coordinar todas las actividades realizadas por el personal de limpieza en las habitaciones, en la recepción, en las zonas comunes del hotel, organizar los trabajos de la plantilla y los turnos.

"Para formarse como Gobernanta de Hotel no se necesita ningún requisito en especial. Muchas de las personas que realizan esta formación ya trabajan como camareras de piso o personal de mantenimiento, y cursan esta formación para conseguir un puesto de mayor responsabilidad".

$<$ http://www.avanzaentucarrera.

com/llegaraser/guia-de-profesiones/

profesiones-de-hosteleria-y-turismo/

gobernanta-de-hotel/>

Nota: No México e em El Salvador, para se referir a essa profissão, utiliza-se o termo ama de llaves.

GOVERNANTA ASSISTENTE s.f. (TND; Hospedagem) 
TERMINOLOGIA BILÍNGUE DESIGNATIVA DAS PROFISSÕES DA HOTELARIA

Esp. Subgobernanta.

Profissional responsável por auxiliar e coordenar as camareiras, o pessoal da limpeza e a lavanderia em suas atividades operacionais, orientando, ensinando e agilizando as atividades.

"A figura da governanta assistente estará presente em hotéis de grande porte”. (Governança, 2012, p. 27).

Profesional reponsable de auxiliar a la gobernanta y coordinar los empleados de áreas públicas, pisos o lavandería y lencería.

"La gobernanta puede estar auxiliada por una o dos subgobernanta que hacen entre ella y el resto del personal del departamento".

<http://www.monografias.com/trabajos82/ proyecto-hotel/proyecto-hotel2.shtml>.

Nota: No México e em El Salvador, para se referir a essa profissão, utiliza-se o termo asistente de la ama de llaves; e, na Venezuela, utiliza-se asistente de mayordomía.

\section{MENSAGEIRO s.m. (TDAD; Hospedagem)}

\section{Esp. Botones.}

Profissional responsável por servir e solucionar os problemas dos hóspedes, por fornecer-lhes a segurança de suas bagagens e de seus pertences, acompanhá-los, em sua chegada, até seu apartamento e por portar boas ou más notícias.

"Quando um hóspede chega ao hotel, o mensageiro, sabendo que há uma reserva, acompanha-o até o balcão da recepção e coloca-se próximo à bagagem, enquanto aguarda o processo de check-in ser finalizado”. (Hotel: Serviços em Hotelaria, 2012, p.67).

Profesional responsable por recibir y servir a los huéspedes y ayudarlos com sus equipajes.

"Empezó de botones, pasó por la centralita, la consejería nocturna y la recepción de día, así durante 50 años, hasta su retiro en 2001".

<http://www.diariodenavarra.es/noticias/navarra/ pamplona_comarca/2015/04/20/el_botones_del_hotel_ perla_203451_1002.html>

Nota: Na Espanha, para se referir a essa profissão, além de botones, utiliza-se, em algumas regiões, o termo mozo de equipajes; no México e no Peru, utilizam-se mensajero ou botones; e, na Venezuela, na Colômbia e em El Salvador, utiliza-se mensajero.

\section{MORDOMO s.m. (TDAD; Hospedagem)}

Esp. Mayordomo.

Profissional responsável por coordenar tanto o check-in como o check-out do hóspede, colher informações sobre este e preservá-las, preparar o local da sua estada e estar disponível para servi-lo desde a sua chegada até a sua saída, atendendo às suas demandas.

"Além disso, caso você queira fazer suas refeições na suíte ou antecipar o pedido do restaurante, o mordomo estará à sua disposição".

$<$ http://www.montblancpremium.com.br/diferencial/ mordomo $>$

Profesional responsable de ofrecer servicio personalizado para los huéspedes.

"Un buen mayordomo sabe lo que tiene que hacer sin que se lo pidamos".

$<$ http://www.traveler.es/viajes/

mundo-traveler/articulos/

hay-un-robot-en-mi-hotel-y-es-mi-mayordomo/ 5887>

\section{RECEPCIONISTA $s .2 g$. (TDAD; Hospedagem) \\ Esp. Recepcionista.}

Profissional responsável por receber os hóspedes ingressantes no hotel, realizar o seu registro check-in conforme a reserva feita pelo departamento de reservas, entregar as chaves do apartamento reservado e, no momento do check-out, ou seja, da saída dos hóspedes, realizar o encerramento das contas.

"Em hotéis de grande porte, cujas equipes são maiores, o primeiro contato do hóspede poderá ser com o capitão-porteiro ou com o mensageiro, porém, em hotéis de pequeno porte ou até mesmo de médio porte, onde as funções poderão não existir, será o recepcionista o responsável por causar uma impressão positiva.” (Hotel: Serviços em Hotelaria, 2012, p.62).

Profesional responsable por recibir a los huéspedes cuando llegan al hotel, formalizar sus entradas y sus salidas y cierrar sus cuentas.

"En este caso, los turnos van según el volumen de trabajo, "si hay mucho, el jefe no se presenta, el resto ya se apañará”, dice la recepcionista”.

<http://www.elmundo.es/elmundo/2010/09/27/ baleares/1285614979.html>

\section{SOMMELIER s.m. (TND; Alimentos e Bebidas)}

Esp. Sumiller.

Profissional responsável por harmonizar bebidas com pratos que constituem o cardápio do restaurante por ser especialista em vinhos e em bebidas alcoólicas em geral.

"Há muitos clientes que estudam os vinhos como hobby e gostam de conversar sobre o assunto quando percebem que no restaurante há um sommelier". (Hotel: Serviços em Hotelaria, 2012, p. 84).

Profesional responsable por sugerir a los clientes cuál 
vino es mejor con cada plato.

"Un buen sumiller siempre debe mantenerse al dia en todas las novedades que surgen en el mundo del vino, a nivel nacional e internacional, y en las diferentes tendencias gastronómicas que se van poniendo de moda".

$<$ http://www.avanzaentucarrera.

com/llegaraser/guia-de-profesiones/

profesiones-de-hosteleria-y-turismo/sumiller/>

Nota 1: O referido termo é proveniente da língua francesa e apresenta-se também no feminino como sommelière. Nota 2: $\mathrm{Na}$ Venezuela, para se referir a essa profissão, utiliza-se o termo catador de vino ou catador de bebidas; e, no Peru, utiliza-se sommelier.

SUPERVISOR DE LAVANDERIA s.m. (TND; Hospedagem)

Esp. Supervisor de lavandería.

Profissional responsável por coordenar e controlar as tarefas do setor de lavanderia.

"Informar ao supervisor da lavanderia quando existir algum problema com as máquinas”. (Administração de Recursos Humanos em Hospitalidade, 2004, p. 77). Profesional responsable de controlar tanto el lavado cuanto el secado de la ropa de los huéspedes y de la lencería del hotel.

"neuvoo.es facilita 16 oportunidades de supervisor de lavanderia en España”.

$<$ http://neuvoo.es/empleos/

trabajo-de-Supervisor-de-Lavander\%C3\%ADa>

Nota: Para se referir a essa profissão em espanhol, podem-se utilizar também os termos encargado de lavandería ou jefe de lavandería.

SUPERVISOR DE RECEPÇÃO s.m. (TND; Hospedagem)

Esp. Jefe de recepción.

Profissional responsável por organizar, dirigir e acompanhar diariamente o trabalho burocrático realizado pelas equipes, a área de recepção e a oferta de apartamentos, visando à ocupação máxima de qualidade, e solucionar situações de hóspedes não resolvidas pela equipe no primeiro contato.

"Outra área ligada ao supervisor de recepção é a de telefonia”. (Hotel: Serviços em Hotelaria, 2012, p. 64).

Profesional responsable por dirigir la area de recepción y por gestionar la oferta de habitaciones del hotel.

"El desarrollo de estas tareas estará coordinado y supervisado por el jefe de recepción, que vigilará la prestación eficiente de servicios a los huéspedes del hotel". (Recepción hotelera y atención al cliente, 2009, p. 8).

Nota: No México, para se referir a essa profissão, utiliza-se do termo supervisor de recepción ou jefe de recepción; na Venezuela, na Colômbia e em El Salvador, utiliza-se o termo supervisor de recepción.

VALETE s.m. (TDAD; Hospedagem)

Esp. Valet.

Profissional responsável por auxiliar a camareira nos serviços mais pesados.

"Logo depois, quase no final do turno, o valete leva até sua cabina a mesma quantidade em roupa limpa". (Camareira de Hotel, 2003, p. 45).

Profesional responsable por hacer la limpieza y los servicios que exigen más fuerza los cuáles el personal femenino no puede realizar.

"Un mozo de habitaciones o valet al igual que cualquier miembro del Departamento de Pisos, es una persona muy valiosa dentro de él y es responsabilidad de la Gobernanta y Subgobernantas es sacar su mayor provecho para conseguir el máximo rendimiento de este personal".

$<$ https://gobernantas.wordpress.com/2010/12/13/ valet-o-mozo-de-habitaciones/>

\section{APRESENTAÇÃO DOS DADOS}

Registraram-se 18 verbetes designativos das profissões da Hotelaria; a apresentação dessa nomenclatura permitiu o estudo de cinco aspectos importantes: o registro da dicionarização dos termos; a indicação das divergências quanto à dicionarização; a indicação da quantidade de termos por subdomínio; a apresentação dos empréstimos linguísticos; e a identificação de termos com equivalência nos diferentes países que utilizam a língua espanhola como oficial.

Estabeleceu-se como corpus de exclusão os dicionários eletrônicos: Aurélio, Caldas Aulete e Michaelis, servindo de parâmetro para a indicação de dicionarização dos termos. Esses parâmetros foram classificados de acordo com o tipo de acepção, podendo ser equivalente (TDAE), complementar (TDAC) ou diferente (TDAD), e não dicionarizados (TND).

A Figura 1 mostra que $67 \%$ são termos não dicionarizados; $22 \%$ são dicionarizados com acepção diferente. Isso revela que uma parte significativa dos termos não está registrada nas grandes obras lexicográficas do português do Brasil, refletindo a falta de atualização dessas grandes obras mencionadas.

Diante de uma variedade de dicionários existentes, nem sempre o surgimento de novas palavras e conceitos 
Apresentação quanto à dicionarização dos termos

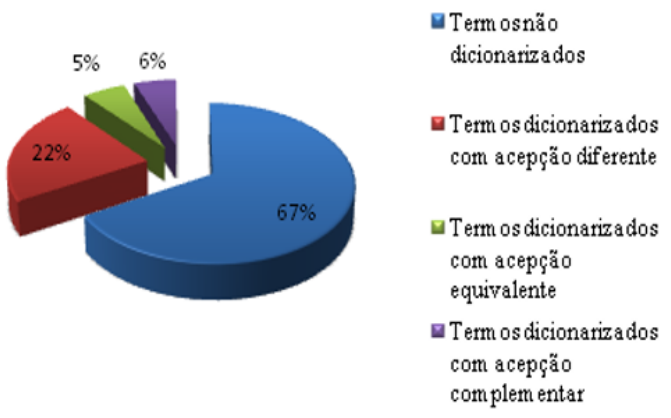

Figura 1: Indicação de dicionarização dos termos. Fonte: dados da pesquisa.

constam em todos esses materiais, e, quando são registrados, às vezes, os conceitos se modificam. Utilizou-se como corpus de exclusão os dicionários eletrônicos $A u$ rélio, Caldas Aulete e Michaelis. A pesquisa realizada nessas três obras da língua portuguesa do Brasil evidenciou que apenas 3 verbetes, dos 18 termos registrados no glossário, apresentaram divergências quanto à dicionarização. Esses termos divergentes são apresentados na Tabela 2

Tabela 2: Inventário de termos com divergências quanto à dicionarização.

\begin{tabular}{|c|c|c|c|}
\hline TERMO & AURÉLIO & $\begin{array}{c}\text { CALDAS } \\
\text { AULETE }\end{array}$ & MICHAELIS \\
\hline Barman & TND & TDAE & TDAE \\
\hline Camareira & TDAE & TDAD & TDAE \\
\hline Sommelier & TND & TDAE & TDAE \\
\hline \multicolumn{4}{|c}{ Fonte: dados da pesquisa. }
\end{tabular}

As divergências de dicionarização são de extrema importância para o presente trabalho, pois registram-se e identificam-se quais os termos que são dicionarizados e os que possuem equivalências, complementos ou divergências em seus significados; quando apresentam termos não dicionarizados significam que os mesmos não constam em nenhum dos três dicionários propostos.

Quanto aos subdomínios, foram identificados: Alimentos e Bebidas (4 termos); Administração (1 termo); Hospedagem (12 termos); e Vendas (1 termo).

$\mathrm{O}$ estudo também identificou 03 empréstimos linguísticos, conforme mostra a Tabela 3 .

Os empréstimos linguísticos são palavras provenientes de uma determinada língua estrangeira e utilizadas no português do Brasil. Essas palavras podem ser classificadas de duas maneiras: denominadas xenismos,

\section{Apresentação quanto aos subdominios}
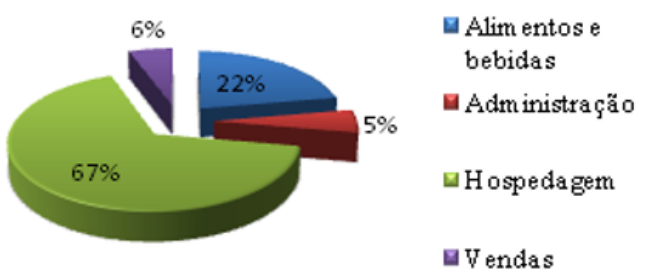

Figura 2: Apresentação quanto aos subdomínios. Fonte: dados da pesquisa.

Tabela 3: Inventário de estrangeirismos. Fonte: Dados da pesquisa

\begin{tabular}{|l|l|}
\hline \multirow{2}{*}{ Estrangeirismos } & Total: 3 (de 18 termos) \\
\cline { 2 - 2 } & Porcentagem: 17\% \\
\hline Barman; concierge; sommelier. \\
\hline \multicolumn{2}{|c|}{ Fonte: dados da pesquisa } \\
\hline
\end{tabular}

se forem dicionarizadas sem adaptações gráficas em dicionários de língua geral da língua portuguesa do Brasil; e estrangeirismos, se não forem dicionarizadas.

A Tabela 4 mostra a variação quanto à equivalência de alguns termos em língua espanhola.

Em alguns casos, a variação na equivalência foi evidenciada por meio de uma sutil mudança na escrita; em outros, ocorreu uma modificação total do equivalente. Entretanto, nesse caso, as modificações na grafia não interferem na definição dos conceitos. 
Tabela 4: Termos com variações na equivalência em espanhol em alguns países onde utilizam a língua como oficial

\begin{tabular}{|c|c|c|c|c|c|c|c|}
\hline Termos & Chile & Colômbia & El Salvador & Espanha & México & Peru & Venezuela \\
\hline $\begin{array}{c}\text { Assistente } \\
\text { de } \\
\text { evento }\end{array}$ & $\begin{array}{l}\text { Asistente } \\
\text { de } \\
\text { producción } \\
\text { de } \\
\text { eventos }\end{array}$ & $\begin{array}{l}\text { Auxiliar } \\
\text { de } \\
\text { eventos }\end{array}$ & $\begin{array}{c}\text { Ayudante } \\
\text { de } \\
\text { eventos }\end{array}$ & $\begin{array}{l}\text { Asistente } \\
\text { eventos }\end{array}$ & $\begin{array}{l}\text { Asistente } \\
\text { eventos }\end{array}$ & $\begin{array}{l}\text { Asistente } \\
\text { eventos }\end{array}$ & $\begin{array}{l}\text { Asistente } \\
\text { eventos }\end{array}$ \\
\hline $\begin{array}{l}\text { Asistente } \\
\text { de } \\
\text { reservas }\end{array}$ & $\begin{array}{c}\text { Asistente } \\
\text { de } \\
\text { reservaciones }\end{array}$ & $\begin{array}{l}\text { Asistente } \\
\text { de } \\
\text { reservas }\end{array}$ & $\begin{array}{c}\text { Asistente } \\
\text { de } \\
\text { reservaciones }\end{array}$ & $\begin{array}{c}\text { Asistente } \\
\text { de } \\
\text { reservaciones }\end{array}$ & $\begin{array}{c}\text { Encargado } \\
\text { de } \\
\text { reservaciones }\end{array}$ & $\begin{array}{l}\text { Asistente } \\
\text { de } \\
\text { reservas }\end{array}$ & $\begin{array}{l}\text { Asistente } \\
\text { de } \\
\text { reservas }\end{array}$ \\
\hline Barman & Barman & Bartender & Barman & Barman & Barman & Bartender & $\begin{array}{c}\text { Bartender/ } \\
\text { Barman }\end{array}$ \\
\hline Camareira & Camarera & Camarera & Mucama & $\begin{array}{c}\text { Camarera } \\
\text { de } \\
\text { piso }\end{array}$ & $\begin{array}{c}\text { Mucama/ } \\
\text { Camarista/ } \\
\text { Marera }\end{array}$ & Camarera & Camarera \\
\hline Gerente geral & $\begin{array}{l}\text { Gerente } \\
\text { general }\end{array}$ & $\begin{array}{l}\text { Gerente } \\
\text { general }\end{array}$ & $\begin{array}{l}\text { Gerente } \\
\text { general }\end{array}$ & $\begin{array}{l}\text { Director } \\
\text { del hotel }\end{array}$ & $\begin{array}{l}\text { Gerente } \\
\text { general }\end{array}$ & $\begin{array}{l}\text { Gerente } \\
\text { general }\end{array}$ & $\begin{array}{l}\text { Gerente } \\
\text { general }\end{array}$ \\
\hline Governanta & $\begin{array}{c}\text { Ama } \\
\text { de } \\
\text { llaves }\end{array}$ & $\begin{array}{c}\text { Ama } \\
\text { de } \\
\text { llaves }\end{array}$ & $\begin{array}{c}\text { Ama } \\
\text { de } \\
\text { llaves }\end{array}$ & Gobernanta & $\begin{array}{c}\text { Ama } \\
\text { de } \\
\text { llaves }\end{array}$ & $\begin{array}{l}\text { Ama } \\
\text { de } \\
\text { llaves }\end{array}$ & $\begin{array}{c}\text { Ama } \\
\text { de } \\
\text { llaves }\end{array}$ \\
\hline $\begin{array}{l}\text { Governanta } \\
\text { assistente }\end{array}$ & $\begin{array}{l}\text { Asistente } \\
\text { de la ama } \\
\text { de llaves }\end{array}$ & $\begin{array}{l}\text { Asistente } \\
\text { de la ama } \\
\text { de llaves }\end{array}$ & $\begin{array}{c}\text { Asistente } \\
\text { de la ama } \\
\text { de llaves }\end{array}$ & Subgobernanta & $\begin{array}{c}\text { Asistente } \\
\text { de la ama } \\
\text { de llaves }\end{array}$ & $\begin{array}{c}\text { Asistente } \\
\text { de la ama } \\
\text { de llaves }\end{array}$ & $\begin{array}{c}\text { Asistente } \\
\text { de la ama } \\
\text { de llaves }\end{array}$ \\
\hline Mensageiro & Mensajero & Mensajero & Mensajero & $\begin{array}{c}\text { Botones/Mozo } \\
\text { de Equipajes }\end{array}$ & $\begin{array}{c}\text { Mensajero/ } \\
\text { Botones }\end{array}$ & $\begin{array}{c}\text { Mensajero/ } \\
\text { Botones }\end{array}$ & $\begin{array}{c}\text { Mensajero/ } \\
\text { Botones }\end{array}$ \\
\hline Sommelier & Sommelier & Sommelier & Sommelier & Sumiller & Sommelier & Sommelier & $\begin{array}{c}\text { Catador } \\
\text { de vino/ } \\
\text { Catador } \\
\text { de } \\
\text { bebidas }\end{array}$ \\
\hline
\end{tabular}

Fonte: dados da pesquisa. 
TERMINOLOGIA BILÍNGUE DESIGNATIVA DAS PROFISSÕES DA HOTELARIA

\section{CONCLUSÃO}

Objetivou-se elaborar um glossário de termos das profissões da Hotelaria e, para isso, foram descritos os verbetes da referida Terminologia, considerando a equivalência com o idioma espanhol da Espanha, e ainda foram verificados aspectos semânticos e morfossintáticos da Terminologia em foco.

Como visto anteriormente, todos os termos repertoriados possuem equivalentes na língua espanhola da Espanha, confirmando a hipótese levantada no início deste trabalho. Quanto ao estudo dos termos deste glossário, verificou-se que a maioria não é dicionarizada, sendo a maior parte deles termos compostos, e a menor, estrangeirismos. Além disso, alguns dos verbetes coletados constam divergências quanto à dicionarização, prejudicando os consultantes quanto ao acesso às informações especializadas. A maior parte dos termos coletados contém variações em espanhol quanto ao uso em diferentes países que utilizam a língua como oficial.

\section{REFERÊNCIAS}

ALVES, L. M. B. Termos designativos da vinicultura brasileira. 2013. Instituto Federal de Educação, Ciência e Tecnologia do Ceará, Fortaleza. Trabalho de Conclusão do Curso Superior em Tecnologia em Hotelaria.

AVANZA. Avanza en tu carrera. 2017. Disponível em: <http://www.avanzaentucarrera. com/llegaraser/guia-de-profesiones/ profesiones-de-hosteleria-y-turismo/director-de-hotel/ >. Acesso em: 26 jul. 2015.

Avanza en tu carrera. 2017. Disponível em: <http://www.avanzaentucarrera. com/llegaraser/guia-de-profesiones/ profesiones-de-hosteleria-y-turismo/ gobernanta-de-hotel/> Acesso em: 28 jul. 2015.

Avanza en tu carrera. 2017. Disponível em: <http://www.avanzaentucarrera. com/llegaraser/guia-de-profesiones/ profesiones-de-hosteleria-y-turismo/ camarera-de-pisos/> Acesso em: 26 jul. 2015.

Avanza en tu carrera. 2017. Disponível em: <http://www.avanzaentucarrera. com/llegaraser/guia-de-profesiones/ profesiones-de-hosteleria-y-turismo/sumiller/> Acesso em: 29 jul. 2015.
. Avanza en tu carrera. 2017. Dispo-

nível em: <http://www.avanzaentucarrera.

com/llegaraser/guia-de-profesiones/ profesiones-de-hosteleria-y-turismo/ camarero-barman/> Acesso em: 02 ago. 2015.

AZEVEDO, D. N. V. Terminologia bilíngue da alfândega brasileira para viajantes. 2012. Instituto Federal de Educação, Ciência e Tecnologia do Ceará, Fortaleza. Trabalho de Conclusão do Curso Superior em Tecnologia em Gestão de Turismo.

CÂMARA, C. S. Governança. Manaus: CETAM, 2012. $27 \mathrm{p}$.

CESAE. Cesae business \& tourism school.

2017. Disponível em: <http://www.cesae.es/ blog/las-5-claves-de-los-puestos-de-trabajo-en-/ hoteles-el-jefe-de-alojamiento> Acesso em: 26 jul. 2015.

CORREA, E. Proyecto de un hotel. 2010. Disponível em: <http://www.monografias.com/trabajos82/ proyecto-hotel/proyecto-hotel2.shtml> Acesso em: 26 jul. 2015 .

CPT. CPT - Centro de Produ-

ções Técnicas. 2017. Disponível em:

<http://www.cpt.com.br/cursos-hotelaria/artigos/ hotelaria-atendente-de-reservas-e-suas-funcoes> Acesso em: 02 ago. 2015.

Diario de Navarra. Diario de Navarra. 2017.

Disponível em: <http://www.diariodenavarra.es/ noticias/navarra/pamplona_comarca/2015/04/20/el_ botones_del_hotel_perla_203451_1002.html > . Acesso em: 03 ago. 2015 .

Dicionário Aurélio. Dicionário eletrônico Aurélio. 2017. Disponível em: <https://dicionariodoaurelio. com/> Acesso em: 03 ago. 2015.

DICIONáRIO eletrônico Caldas Aulete. Disponível em: <http://www.aulete.com.br/>

DICIONáRIO eletrônico Michaelis UOL. Disponível em: <http://michaelis.uol.com.br/>

El Mundo. El Mundo. 2017. Disponível em: $<<$ http://www.elmundo.es/elmundo/2010/09/27/ baleares/1285614979.html> Acesso em: 28 jul. 2015.

El Periodico. El Periodico. 2017. Disponível em: <http://www.elperiodico.com/es/noticias/ 
TERMINOLOGIA BILÍNGUE DESIGNATIVA DAS PROFISSÕES DA HOTELARIA

barcelona/empleado-hotel-barcelona-opta-premio/ mejor-conserje-2883369>, Acesso em: 03 ago. 2015.

FARIAS, E. M. P. Glossário de Termos da Moda. Fortaleza: UFC, 2003.

FREITAS, B. M. R. d. Os termos técnicos da coquetelaria no setor hoteleiro. 2009. Instituto Federal de Educação, Ciência e Tecnologia do Ceará, Fortaleza. Trabalho de Conclusão do Curso Superior em Tecnologia em Hotelaria.

GARCIA, M. E. Absorção de mão-de-obra, escolaridade e salários na hotelaria brasileira. Revista Eletrônica Turismo em Análise, São Paulo, 1996. Disponível em: <https://www.revistas.usp.br/rta/ article/download/63253/66037> . Acesso em: 26 jul. 2015.

GOBERNANTA'S. Gobernanta's blog. 2017. Disponível em: <https://gobernantas.wordpress.com/ 2010/12/13/valet-o-mozo-de-habitaciones/> Acesso em: 28 jul. 2015.

GOMES, D. P. Sejam bem-vindos: termos e expressões técnicas do setor hoteleiro com enfoque na recepção. 2009. Instituto Federal de Educação, Ciência e Tecnologia do Ceará, Fortaleza. Trabalho de Conclusão do Curso Superior em Tecnologia em Hotelaria.

HIGES, R. B.; MIRA, M. C. D.; YUSTE, M. I. G. C.; GÓMEZ, E. C. S.; LÓPEZ, R. M. B.; JUNCO, M. L. R.; MARCOS, V. C.; GARCÍA, M. P. R.; PEDRO, M. P. L.; REDONDO, F. O.; CABRIA, A. B. Guía sectorial de la formación de profesionales en España. Madrid: INEM, 2002. 609 p.

JOBOMAS. Jobomas. 2017. Disponível em: <http: //es.jobomas.com/auditor-nocturno-hoteles-barcelona_ iid_37937201> Acesso em: 28 jul. 2015.

KRIEGER, M. G.; FINATTO, M. J. B. Introdução à Terminologia: teoria e prática. 1. ed. São Paulo: CONTEXTO, 2004.

MATOS, A. V. Vocabulário semi-sistemático da terminologia do caranguejo. Dissertação (Mestrado em Linguística) - Universidade Federal do Pará, Belém, 2001.

Mont. Mont Blanc Premium. 2017. Disponível em: <http://www.montblancpremium.com.br/diferencial/ mordomo $>$ Acesso em: 03 ago. 2015.
NEUVOO. Neuvoo. 2017. Disponí-

vel em: <http://neuvoo.es/empleos/ trabajo-de-Asistente-de-Eventos-en-Madrid> Acesso em: 29 jul. 2015.

Neuvoo. 2017. Disponível em: <http://neuvoo. es/empleos/trabajo-de-Supervisor-de-Lavander\%C3\% ADa> Acesso em: 28 jul. 2015.

NOGUEIRA, A. C. S. Arte em açúcar: sobremesas luso-brasileiras. 2009. 97 p. Instituto Federal de Educação, Ciência e Tecnologia do Ceará, Fortaleza. Trabalho de Conclusão do Curso Superior em Tecnologia em Hotelaria.

NUVENS, M. A. Elementos para um glossário dos termos da cultura, industrialização e comercialização da cana-de-açúcar. Dissertação (Mestrado Acadêmico em Linguística Aplicada) Universidade Estadual do Ceará, Fortaleza, 2006.

OLIVEIRA, G. B.; SPENA, R. Hotel: Serviços em Hotelaria. São Paulo: SENAC, 2012.

Portal Educação. Portal Educação. 2017.

Disponível em: <http://www.portaleducacao. com.br/turismo-e-hotelaria/artigos/18726/ caracteristicas-da-auditoria-noturna> Acesso em: 28 jul. 2015.

Revista Hoteis. Revista Hoteis. 2017. Disponível em: <http://www.revistahoteis.com.br/ sheraton-rio-tem-novo-diretor-de-ab/> Acesso em: 26 jul. 2015.

Rincon del Vago. Rincon del Vago. 2017.

Disponível em: <http://html.rincondelvago.com/ reservas-en-hoteles.html> Acesso em: 26 jul. 2015.

SILVA, L. C. d. Termos e expressões técnicas da governança hoteleira. 2010. Instituto Federal de Educação, Ciência e Tecnologia do Ceará, Fortaleza. Trabalho de Conclusão do Curso Superior em Tecnologia em Hotelaria.

TANKE, M. L. Administração de Recursos Humanos em Hospitalidade. São Paulo: THOMSON, 2004. 77 p.

TRAVELER. Traveler. 2017. Disponível em: <http: //www.traveler.es/viajes/mundo-traveler/articulos/ hay-un-robot-en-mi-hotel-y-es-mi-mayordomo/ 5887> Acesso em: 02 ago. 2015.

UREÑA, A. N. Recepción hotelera y atención al cliente. 1. ed. Madrid: PARANINFO, 2009. 8 p. 
VIERA, E. V. Camareira de Hotel. 2. ed. Canoas:

ULBRA, 2003. 45 p. 